\title{
Regional policy in a multiregional setting: when the poorest are hurt by subsidies
}

\author{
Nicholas Sheard ${ }^{1,2}$ \\ Department of Economics, Stockholm University
}

March 2011

\begin{abstract}
Regional policies that seek to reduce economic inequalities between regions are common. These policies normally involve subsidies or transfers to the poorest regions. Over any given short-term horizon such subsidies serve to reduce inter-regional inequalities, but as they also affect migration patterns the long-term effects are less clear. This paper demonstrates using a three-region, general equilibrium model that subsidising the poorest region may be to the detriment of the periphery as a whole and even to the very region that receives the subsidy, if the subsidy draws firms away from a nearby region that would function better as a production centre. Though further research is needed to isolate the conditions under which such an effect would arise, the result has potentially important implications for the design of regional policy.
\end{abstract}

Keywords: regional policy; production externalities; agglomeration; multiregion model

JEL classification: H2, R12, R13

\section{Introduction}

The inequalities in per-capita production and income levels between regions can be large, usually with more wealth generated in those regions that have larger concentrations of firms and population. In Europe, for example, the regions comprising London, Brussels, Hamburg, Prague, and Bucharest each generate more than twice the GDP per capita of the lowest income regions in the same countries (Commission, 2007). Due to production externalities and the benefits of locating near more and wealthier customers, these regions are also

\footnotetext{
${ }^{1}$ Stockholm University, Department of Economics, 10691 Stockholm, Sweden. Tel: +46 81630 39. Fax: +46 81594 82. E-mail: ns@ne.su.se.

2 The author thanks Rikard Forslid, Karolina Ekholm, Yves Zenou, Shon Ferguson, Mark Bernard, Paulo Cox, Jørn Rattsø, Steven Brakman, and seminar participants at Stockholm University, Monash University, the 2009 ENTER Jamboree at University College London, and NTNU for comments and suggestions. Any remaining errors are my own.
} 
attractive locations for firms. These inter-regional inequalities therefore provide an incentive for firms and individuals to migrate, which is reflected in empirical evidence showing that economic activity in most parts of the world is currently becoming more agglomerated (United Nations, 2007).

Over time, migration driven by a pursuit of higher standards of living serves to reduce the gap in standards of living between regions, with two caveats. Firstly, the cost of migration implies a direct disadvantage for residents of poorer regions who must move to attain the higher standard of living; indeed it would not be worth moving if the gain in standard of living does not exceed the cost of migration. And secondly, the inertia in location choice permits inter-regional inequalities to exist until a new steady state allocation obtains.

In order to reduce inter-regional inequalities, many governments institute regional policies that promote production or directly aid individuals in poorer regions through a system of subsidies or transfers. A conspicuous example is the regional policy conducted by the European Union (EU) through its Structural and Cohesion Funds, which currently represent $36 \%$ of the EU's total budget, while the governments of EU member states also pursue their own regional policies in parallel ${ }^{3}$. Elsewhere, subsidy and transfer schemes are employed in most developed and even many developing countries, with various schemes instituted in the United States, Canada, Australia, Switzerland, Turkey, Russia, and China, to name but a few examples. A substantial component of these policies is regional subsidies: a combination of subsidies to firms, individuals, and infrastructure in poorer regions. The principle underlying such policies is that a marginal improvement in conditions in the poorer regions brought

\footnotetext{
${ }^{3}$ In the current period, spanning the years from 2007 to 2013, the EU has allocated $€ 308$ billion to these policies, up from $€ 213$ billion for the period from 2000 to 2006, which amounts to around $0.4 \%$ of EU countries' GDP (Commission, 2008). These amounts are topped up by national spending, which prior to the EU's 2004 expansion was more than 1\% of EU countries' GDP (Commission, 2006).
} 
about by an increase in wages, employment, or local services will lead to a reduction in interregional inequalities. In a system of two regions, this holds true. However, the effects of such a policy in a system comprised of many regions, particularly when considering migration, are less clear.

It was pointed out by Assar Lindbeck in the 1960s that, in light of local production externalities, inducing firms to locate in an area with poor natural conditions rather than in a nearby area that would support a cluster of production could threaten the survival of the cluster (Lindbeck, 1964). Though intuitive and relevant to the application of regional policy, to the best of my knowledge the idea is yet to be given a solid analytical foundation.

The current paper formalises this idea by demonstrating in a rigorous manner, using a threeregion general equilibrium model, that a subsidy to the poorest region may actually hurt it in the long-run by drawing firms away from a nearby region that would more naturally function as a centre of production. Due to externalities in production and the effects on migration patterns, the positive effect on production in the subsidised region may be offset by a larger and more permanent decrease in production in the neighbouring region, so that agglomeration to the distant 'core' of the system represented by a more densely populated and productive region is made more acute. As a consequence, individuals residing in the periphery have worse employment opportunities and face higher consumer prices due to the costs of importing goods from further away. This implies a lower real wage and therefore a lower standard of living for residents of the periphery, including those in the region that receives the subsidy.

The results presented in this paper imply that the most effective method for improving economic opportunity in the poorest regions may not be to subsidise those regions directly, indeed this could be worse than doing nothing. Instead, this paper raises the possibility that 
in some cases it would be better to subsidise locations that have greater potential to support production. Further research is required to determine the conditions under which such a scenario would arise in reality and how such conditions could be identified, but the potential for poor-region subsidies to increase inter-regional inequality should be of concern to policymakers.

Much of the existing economic theory on regional policy supports the apparently obvious notion that providing a subsidy to poorer regions is to their benefit and therefore promotes equality, though perhaps at the expense of growth in the economy as a whole (Martin, 1999a; Ulltveit-Moe, 2007). This inference depends, however, on how the funds are spent. A known potential flaw in regional policy design relates to improvements in transport infrastructure. Though improving transport links within a region directly aids economic activity in that region, improving the link between a more- and a less-developed region can enhance agglomeration to the more-developed region and thereby increase inequality, as firms relocate to the more-developed region to take advantage of the more profitable local market and simply export their products back to the less-developed region (Martin and Rogers, 1995; Martin, 1999b). This reasoning has been used to explain the relocation of firms from the south of Italy that followed improvements in roads between the north and the south of the country after the Second World War (Faini, 1983), as well as the increased agglomeration to already wealthy regions in Spain and Portugal that followed improvements to the highway networks in the 1980s and 1990s (Holl, 2004; Teixeira, 2006). It has also been noted that if capital is 'footloose', so that it may be allocated anywhere in the economy and the profits repatriated, then providing subsidies to firms in poorer regions may in fact constitute an implicit transfer from poor to rich regions that enhances inter-regional inequality (Dupont and Martin, 2006). Furthermore, Baldwin and Okubo (2006) noted that when firms are heterogeneous in terms of productivity, regional subsidies induce only low 
productive firms to the subsidised region, these firms having the least to lose by relocating from the 'core' of the economy, which limits the effectiveness of the subsidies.

The current paper contributes to this literature by demonstrating a further potential pitfall in the design of regional policy, which in turn demonstrates the importance of production externalities and migration dynamics to the allocation of subsidies. It is shown that if migration is allowed for in a system with multiple regions, a subsidy to a poor region may actually be harmful to its inhabitants in the long-run, supporting Lindbeck's hypothesis. The negative effect of the subsidy occurs without the subsidy being required to 'backfire' as in the footloose capital model and the mechanism does not depend on any changes to transport costs. Rather, in this paper it is demonstrated that the subsidy could be harmful to the residents of the poor, recipient region by inducing convergence towards a less favourable long-term allocation of economic activity. In this scenario, by promoting activity in the poor region, the subsidy draws firms away from a nearby cluster that would otherwise have been self-sustaining due to production externalities but drops below the threshold mass of production required to persist as a cluster, while also failing to establish the subsidised region as a production centre. As residents of the poor region also benefit from a nearby cluster, in the long-run the overall effect of the subsidy may be negative.

The result is explained intuitively and demonstrated with reference to simulations for a given set of parameter values. The use of simulations raises the obvious question of generality. However, this is less problematic in the current context for three reasons. Firstly, the intention is simply to demonstrate that an effect of this type is possible under reasonable conditions, rather than to argue that it would necessarily occur under specific conditions. Secondly, the result emerges for all parameter specifications that produce migration dynamics that are qualitatively similar to those presented here, with agglomeration in the long-term to 
either the largest one or two regions, depending on the initial distribution of manufacturing. Indeed, such dynamics were selected because they are a good stylised approximation of empirical migration patterns. And thirdly, the same result would obtain from any other model that shares certain basic characteristics with the model presented here. Namely, for a three-region model in which (1) the proximity of production is a positive factor in the real wages of workers; (2) net migration to a region is monotonically increasing in the real wage relative to other regions; (3) a subsidy to a region increases the local real wage such that net migration increases in the short-term; (4) one region has strong enough in-migration and another has strong enough out-migration for these rates not to be reversed by the subsidy; and (5) the remaining region is nearer the strong out-migration region in terms of transport costs and would support production in the long-term only in the absence of a subsidy to the strong out-migration region that would draw production away from it, the subsidy to the strong outmigration region makes agglomeration more acute and is detrimental to that region's inhabitants in the long-term.

The result does not emerge from a two-region version of the model, as the region receiving the subsidy would simply benefit from an inflow of tax revenue and eventually firms from the unsubsidised region, but obtains for a reasonable range of parameter values for three regions. With a larger number of regions, the range of parameter values for which this situation arises for at least one region expands ${ }^{4}$. The possibility of such an effect should be considered in the design of regional policy, with care taken not to attract economic activity away from key, potentially healthy regions by the application of subsidies elsewhere.

\footnotetext{
${ }^{4}$ This intuitive point is supported by further simulations not included in the paper.
} 
As the purpose of this paper is to establish that a subsidy to a poor region may increase inequality by the mechanism explained above, a comprehensive analysis of the welfare effects of regional subsidies, a separate exercise that would require a vastly more detailed model and extensive calibration, is not attempted. As such, the absolute welfare effects of the subsidy are not interpreted, these being dependent on a number of subjective factors in the model design. Therefore, this paper does not offer assessments of the overall effects of subsidies or of the potential inefficiency of agglomeration as studied by Matsuyama and Takahashi (1998).

The analysis in this paper uses the core-periphery model of Krugman (1991), which has the dual features relevant to this analysis of allowing for the migration of labour and the agglomeration of production. Given these features, the Krugman model is relatively simple, being comprised of two sectors, manufacturing and agriculture, each of which uses a specific type of labour as the sole production factor for that sector. The model generates agglomeration in a transparent and intuitive way, through externalities in production and mobility of labour, driven by real wage differentials, in the manufacturing sector. The agricultural or traditional sector is operated by immobile workers who represent the permanent population of each region, ensuring that agglomeration does not occur for all parameter values. This model is appropriate to a world where workers and firms migrate between regions, as occurs in reality. Moreover, the model is simulated with initial population patterns that are not in steady state, which reflects current migration trends in most countries as people in general migrate to wealthier and more densely populated regions, often large urban agglomerations ${ }^{5}$. The model does not allow for overall population growth,

\footnotetext{
${ }^{5}$ In Europe and Japan, the rates of out-migration from many sparsely populated, rural areas and in-migration to several of the largest agglomerations exceed half a percent of the populations of these areas per year (Commission, 2007; Statistics Bureau, 2009). The rates of internal migration in the United States are even
} 
a simplification that makes the model clearer without affecting the main results ${ }^{6}$. To analyze the effects of regional subsidies, a government is introduced into the model that has the objective of improving welfare equality in the long-term. The government pursues this goal by exogenously providing subsidies to manufacturing firms in any region of its choice, which it funds by levying labour taxes on all workers in the economy.

The remainder of this paper is arranged as follows: the model is presented in section 2; the dynamics of a system of three regions are presented in section 3; the effects of subsidies on such a system are demonstrated in section 4; and concluding remarks are given in section 5 . The appendices contain further examples of three-region systems, an analysis of the full parameter space, and a proof.

\section{Model}

The model developed in this paper is based on the core-periphery model of Krugman (1991), which provides a powerful and instructive framework for understanding the location of economic activity. The model is composed of a monopolistically competitive manufacturing sector operated by mobile workers and a classical, perfectly competitive agricultural or 'traditional' sector operated by immobile workers. Labour is the sole production factor in each sector, though each uses a distinct type of worker who cannot be retrained to work in the other sector. All workers in the economy are assumed to have identical preferences characterised by the utility function $U=C_{M}^{\mu} C_{A}^{1-\mu}$, where $C_{M}=\left[\int_{0}^{N} c_{i}^{\frac{\sigma-1}{\sigma}} d i\right]^{\frac{\sigma}{\sigma-1}}$ is a composite index of consumption levels of the continuum of the $N$ varieties of manufactured goods and

\footnotetext{
stronger, with many regions experiencing net in- or out-migration at greater than two percent per year (US Census Bureau, 2006).

${ }^{6}$ In any case rates of overall population growth are mostly small relative to rates of internal migration. Indeed, the total population levels of many developed countries are nearly static, despite strong internal migration (United Nations, 2007).
} 
$C_{A}$ is the consumption level of agricultural goods. The parameter $\mu$ determines the proportion of income spent on manufactured goods and $\sigma>1$ represents the demand elasticity of all manufactured goods.

Firms in the manufacturing sector are assumed to use an identical, increasing returns to scale technology represented by the production function $l_{j}=f+\beta x_{j}$, where $l_{j}$ denotes the labour employed and $x_{r}$ denotes the firm's output. As all firms in a given region have the same technology and market access, the equilibrium prices and production levels are identical for all firms within any particular region. Therefore, it simplifies notation to consider the continuum of $n_{r}$ manufactured goods produced in region $r$, each with producer price $p_{r}$ and production level $x_{r}$. The economy is comprised of $R$ regions, so $N=\sum_{r=1}^{R} n_{r}$.

Transport costs in the manufacturing sector are assumed to be of the iceberg variety, with factor $\tau_{r s}>1$ indicating the amount of the good that must be shipped from region $r$ for one unit to arrive in region $s^{7}$. The consumer price in region $s$ for a good produced in region $r$ is therefore $\tau_{r s} p_{r}$. Taking these prices as given and solving the utility maximization problems of individuals in each region yields the demand for a manufactured good produced in region $r$, including the portion that melts away in transit:

$$
x_{r}=\sum_{s=1}^{R} \frac{\tau_{r s}^{1-\sigma} p_{r}^{-\sigma}}{P_{s}^{1-\sigma}} \mu Y_{s}
$$

\footnotetext{
${ }^{7}$ It is assumed that transport costs are symmetrical, so that $\tau_{s r} \equiv \tau_{r s}$ for all combinations of $r$ and $s$, and that transport of goods within a region is not costly, so that $\tau_{r r} \equiv 1$ for all $r$.
} 
The variable $Y_{s}$ represents the total expenditure of individuals in region $s$, which is equal to their total net income as there is no saving or borrowing mechanism. The price index for an individual living in region $r$ is then:

$$
P_{r}=\left[\sum_{s=1}^{R} n_{s} \tau_{s r}^{1-\sigma} p_{s}^{1-\sigma}\right]^{\frac{1}{1-\sigma}}
$$

Extending the price index to include the agricultural good yields the cost-of-living index $p_{A}^{1-\mu} P_{r}^{\mu}$, which conveniently deflates income to yield an expression for indirect utility. The agricultural good is assumed to be produced using a constant returns to scale technology and to be subject to perfect competition, so that agricultural workers simply receive their marginal products, and to be costless to transport, so that its price is uniform throughout the economy. Without loss of generality, it is assumed that this price is equal to one and that production requires one unit of labour per unit of output, so $p_{A}=w_{A}=1$. This simplifies the cost-ofliving index in region $r$ to $P_{r}^{\mu}$ and, given nominal wage $w$, the real wage to $\varpi=w / P_{r}^{\mu}$. The numbers of manufacturing and agricultural workers in region $r$ are denoted $L_{r}^{M}$ and $L_{r}^{A}$. Workers cannot transfer between industries and neither population is subject to growth. Manufacturing workers are able to migrate to capture increases in welfare, so the number of manufacturing workers in each region is variable in the long-term, though the total number in the economy, $L^{M}=\sum_{r=1}^{R} L_{r}^{M}$, is fixed. Agricultural workers are immobile and hence the number in each region is fixed. As there are no immobile factors in the manufacturing sector, the number of agricultural workers is considered to be the permanent or 'structural' size of the region. 


\subsection{Government}

The Krugman (1991) model is modified to include a government that seeks to reduce inequalities between regions by use of a single policy instrument: subsidies to firms in selected regions, financed by income taxes levied throughout the economy. The government chooses subsidy levels for each region, which reduce the fixed costs of operating manufacturing firms in those regions by specified proportions. The income tax is levied on all workers in both sectors of the economy, at a flat rate that is endogenously determined to fund the subsidies exactly.

While the agricultural workers in this model are assumed to be immobile, the manufacturing workers are able to migrate between regions and do so if this improves their welfare. In the long-run, the welfare levels of all manufacturing workers in the economy converge, as they migrate to capture any potential welfare improvement. On the other hand, the immobility of the agricultural workers allows persistent inequalities to exist between them. In effect, location is only a determinant of welfare to the extent that workers are immobile, so it is naturally the agricultural workers who represent the targets of regional policies aimed at reducing inter-regional inequalities. The government's objective is therefore defined to be the reduction of long-term inequalities between the standards of living of agricultural workers in different regions ${ }^{8}$.

The subsidies are assumed to contribute to the fixed rather than the per-unit costs to reflect the application of regional subsidies in practice, with subsidies often directed towards the establishment of firms or infrastructure improvements, objectives that are more closely related to the fixed costs in the current model. This assumption is not crucial, however, as the

\footnotetext{
${ }^{8}$ The government is assumed not to discount the welfare of future generations in its calculations, so that relative values of 'long-term' welfare are analogous to ‘steady state' welfare.
} 
main results of the model would be qualitatively the same if the subsidies were instead applied to the per-unit cost, or indeed to both the fixed and the per-unit costs.

\subsection{Production}

Firms in the manufacturing sector use a common technology that involves a fixed cost for each firm and a constant per-unit cost, so that production exhibits increasing returns to scale. The government may subsidise firms in region $r$ by contributing an exogenous proportion $s_{r}$ of the firms' fixed costs, so that the production function experienced by the firm is in effect:

$$
l_{r}=\left(1-s_{r}\right) f+\beta x_{r}
$$

Given the prevailing manufacturing wage of $w_{r}$, the firm maximises profits given by:

$$
\pi_{r}=p_{r} x_{r}-w_{r}\left(1-s_{r}\right) f-w_{r} \beta x_{r}
$$

Without loss of generality, the units of $x_{r}$ are normalised so that $\beta=\frac{\sigma-1}{\sigma}$. Therefore, the firm maximises profits by setting its price $p_{r}$ to satisfy:

$$
p_{r}=w_{r}
$$

Firms are assumed to enter and exit the economy freely, so that profits are driven to zero, which yields the following condition:

$$
x_{r}=\sigma\left(1-s_{r}\right) f
$$

The amount produced by each manufacturing firm is decreasing in the level of subsidy that it receives. This is because by subsidising the fixed cost, the government reduces the barriers to entry, so firms break even at a lower level of production. At this level of output, and given that $L_{r}^{M}$ manufacturing workers are located in region $r$, it follows from the labour requirements of each firm that the number of manufactured goods produced in region $r$ satisfies: 


$$
n_{r}=\frac{L_{r}^{M}}{\left[\sigma-(\sigma-1) s_{r}\right] f}
$$

In the short-term, in which the proportion of manufacturing in region $r$ is fixed at the level indicated by the number of workers $L_{r}^{M}$, the number of firms operating in that region is increasing in the level of the subsidy. If the subsidy attracts manufacturing to the region, the long-term increase in the number of firms will be greater than the short-term increase.

\subsection{Subsidies and taxation}

In order to fund the subsidies the government must raise revenue, which it is assumed to do by levying a flat, proportional tax on labour throughout the economy at rate $t$. As individuals supply their labour inelastically, this tax is effectively lump-sum and therefore non-distortionary. Given the subsidy levels, the tax rate is determined endogenously so that the government's budget is balanced. The nominal net wage of a manufacturing worker in region $r$ is $w_{r}^{n}=(1-t) p_{r}$ while the nominal net wage of all agricultural workers is $w_{A}^{n}=(1-t)$. The total net income of individuals in region $r$, by definition $Y_{r}=w_{A}^{n} L_{r}^{A}+w_{r}^{n} L_{r}^{M}$, may therefore be expressed as:

$$
Y_{r}=(1-t)\left[L_{r}^{A}+p_{r} L_{r}^{M}\right]
$$

The government is assumed not to have any facility to borrow or lend, so it must keep a balanced budget. The government's budget constraint is therefore:

$$
\sum_{r=1}^{R} n_{r} p_{r} s_{r} f=\left(\frac{t}{1-t}\right) \sum_{r=1}^{R} Y_{r}
$$

The left hand side of (6) represents the government's expenditure on the subsidy scheme, for each region the product of the number of firms, the cost of labour utilising $p_{r}=w_{r}$, the proportional level of the subsidy, and the fixed cost in labour units. The right hand side of (6) 
represents the government's revenue, simply the tax rate multiplied by gross labour income for the whole economy.

The short-term equilibrium is the combination of $n_{r}, x_{r}, p_{r}, P_{r}$, and $Y_{r}$ for each region, along with the tax rate $t$, that solves the system of equations (1) to (6). The short-term equilibrium takes $L_{r}^{M}$, the number of manufacturing workers in each region, as given.

\subsection{Welfare and migration}

The welfare of a worker is analogous to the real net wage, defined as the nominal net wage deflated by the cost-of-living index. The real net wage of a manufacturing worker in region $r$ is:

$$
\varpi_{r}=\frac{w_{r}^{n}}{P_{r}^{\mu}}
$$

And the real net wage of an agricultural worker in region $r$ is:

$$
\psi_{r}=\frac{w_{A}^{n}}{P_{r}^{\mu}}
$$

The proportion of manufacturing workers who are located in region $r$ is denoted $\lambda_{r}$, so by definition $L_{r}^{M} \equiv \lambda_{r} L^{M}$ for each $r$ and $\sum_{r=1}^{R} \lambda_{r}=1$. Manufacturing workers are able to migrate between regions and do so if this improves their welfare. As in Fujita, Krugman, and Venables (1999), the migration of manufacturing workers between any given pair of regions is assumed to be proportional to the populations of both regions and to the discrepancy in welfare levels:

$$
\dot{\lambda}_{r}=\gamma\left(\varpi_{r}-\bar{\varpi}\right) \lambda_{r}
$$

The $\gamma$ parameter determines the speed of migration and $\bar{\varpi}=\sum_{r=1}^{R} \lambda_{r} \varpi_{r}$ is the average real net wage of manufacturing workers in the economy. Workers migrate between any given 
pair of regions if this improves their welfare and the rate at which they migrate is increasing in the difference in welfare levels ${ }^{9}$. Therefore, in aggregate there is out-migration from regions with below-average welfare levels and in-migration to regions with above-average welfare levels. This reflects the relationship between GDP per capita and migration observed in practice (Commission, 2007; US Census Bureau, 2006; Statistics Bureau, 2009).

A long-term equilibrium is defined to be a situation where all of the conditions for short-term equilibrium defined by equations (1) to (6) are satisfied, and no manufacturing workers have an incentive to migrate, so that the right hand side of (7) is equal to zero for all regions. This implies an identical standard of living in the long-run for all manufacturing workers in the economy, either because all regions provide the same standard of living, or because all workers have migrated away from those regions that would have provided a lower standard of living.

\subsection{Agglomeration and dispersion forces}

As migration in the model occurs exclusively in the manufacturing sector, the concepts of agglomeration and dispersion are only relevant to manufacturing activity. The migration of manufacturing workers, which they undergo to capture welfare improvements, implies the movement of firms. Agglomeration forces result from the incentives that manufacturing workers have to locate near manufacturing firms, as this provides relatively inexpensive access to these firms’ products, and to other manufacturing workers, as firms similarly benefit from having customers nearby and can therefore afford to pay higher wages. These incentives naturally involve an element of circular causality. Dispersion forces result from

\footnotetext{
${ }^{9}$ Though the workers in the model are not forward-looking, Baldwin (1999) demonstrated that with sufficiently high quadratic migration costs in a core-periphery model, forward-looking agents' behaviour is equivalent to that of short-sighted agents.
} 
competition over sales to the immobile agricultural workers in each region, who represent a permanent source of local demand.

In general, the dispersion forces in the model are relatively prominent for higher levels of transport costs, so dispersion forces tend to dominate if transport costs are high, while agglomeration forces tend to dominate if transport costs are low. Furthermore, due to the circular causality in agglomeration forces, for some intermediate levels of transport costs there exists a threshold level of manufacturing for a region, above which agglomeration forces dominate but below which dispersion forces dominate.

\section{Multi-region dynamics}

Though economic studies of regional policy are commonly based on the analysis of tworegion models, real world regional systems are clearly more complex. The dynamics that emerge from two-region models are inherently limited, as each region has a single trading partner and a single competitor for mobile factors of production, whereas the balance within systems of three or more regions is more nuanced, due to the potentially elaborate arrays of causal effects. To understand the dynamics of real regional systems, it is therefore important to go beyond the analysis of two-region models. The analysis in this paper is based on systems of three regions: sufficiently many to allow the emergence of certain 'multi-region' dynamics, which also emerge for systems with any larger number of regions, without preventing observation of the general dynamics.

The dynamics of a symmetrical system of three regions, with identical numbers of agricultural workers in each region and a common transport cost factor, $\tau$, for all pairs of regions, were analyzed by Fujita, Krugman, and Venables (1999). They noted the extension from the two-region case of the relationship between transport costs and the relative strength 
of agglomeration and dispersion forces: agglomeration forces tend to dominate when $\tau$ is low, while dispersion forces tend to dominate when $\tau$ is high.

In reality, regions are heterogeneous in terms of structural sizes and the costs of transporting goods between them. A wide range of possible configurations is therefore possible, though in this paper the most relevant case is a sort of dual core-periphery structure that is broadly representative of the type of economic geography landscape that exists in reality. In this type of system there is a heavily-populated region that provides attractive conditions for manufacturing due to its large local market and is therefore experiencing in-migration, a sparsely-populated region with a small local market that is experiencing out-migration, and an intermediately-sized region that is experiencing weak in- or out-migration. The large region forms the 'core' of the entire system, with the 'periphery' made up of the two smaller regions, within which the intermediately-sized region forms a kind of local 'core'.

The regions are numbered in descending order of their structural size, so that region 1 is the largest and so on. In order to simplify things somewhat, but without losing much in the way of generality, it is assumed that it is equally costly to transport goods from region 1 to either of the peripheral regions, while transporting goods between the two peripheral regions is relatively less costly. This type of arrangement is represented qualitatively by Figure 1. 


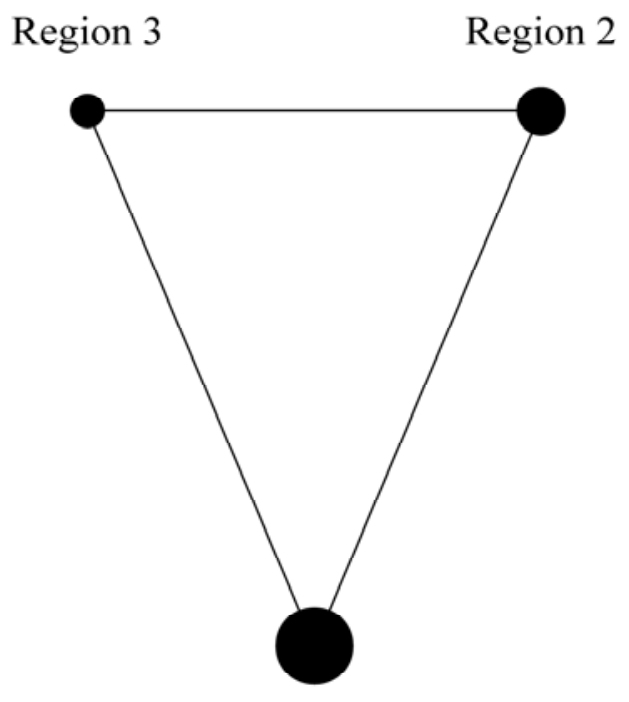

Region 1

Figure 1. Structural arrangement of the three-region system.

With a three-region system, it is possible to observe the dynamics of the population of manufacturing workers according to the assumed migration rule (7) on a ternary diagram, which exploits the fact that the proportions of manufacturing workers in all regions must sum to one to represent the set of all possible distributions of these workers between the three regions as points on a two-dimensional plane. Figure 2 illustrates a numerical example ${ }^{10}$. Each point on the plane in Figure 2 represents a short-term equilibrium, with the magnitude of each $\lambda_{r}$ given by the perpendicular distance from the edge opposite the vertex labelled with that variable. The arrows represent the direction and intensity of migration that results from short-term inter-regional differences in the welfare levels of manufacturing workers according to (7). The filled circles represent stable long-term equilibria, while the unfilled circles represent unstable long-term equilibria. The curved line that cuts through the middle of the triangle represents a 'watershed border', which divides the set of all potential

\footnotetext{
${ }^{10}$ The model parameters are assumed to be $\mu=0.4, \sigma=5, f=1$, and $\gamma=1$, as in Fujita et al. (1999). The numbers of agricultural workers are assumed to be $L_{1}^{A}=3, L_{2}^{A}=2$, and $L_{3}^{A}=1$. The transport costs are assumed to be $\tau_{12}=2.0, \tau_{13}=2.0$, and $\tau_{23}=1.5$.
} 
distributions of manufacturing into subsets from which all initial distributions converge to a common long-term equilibrium.

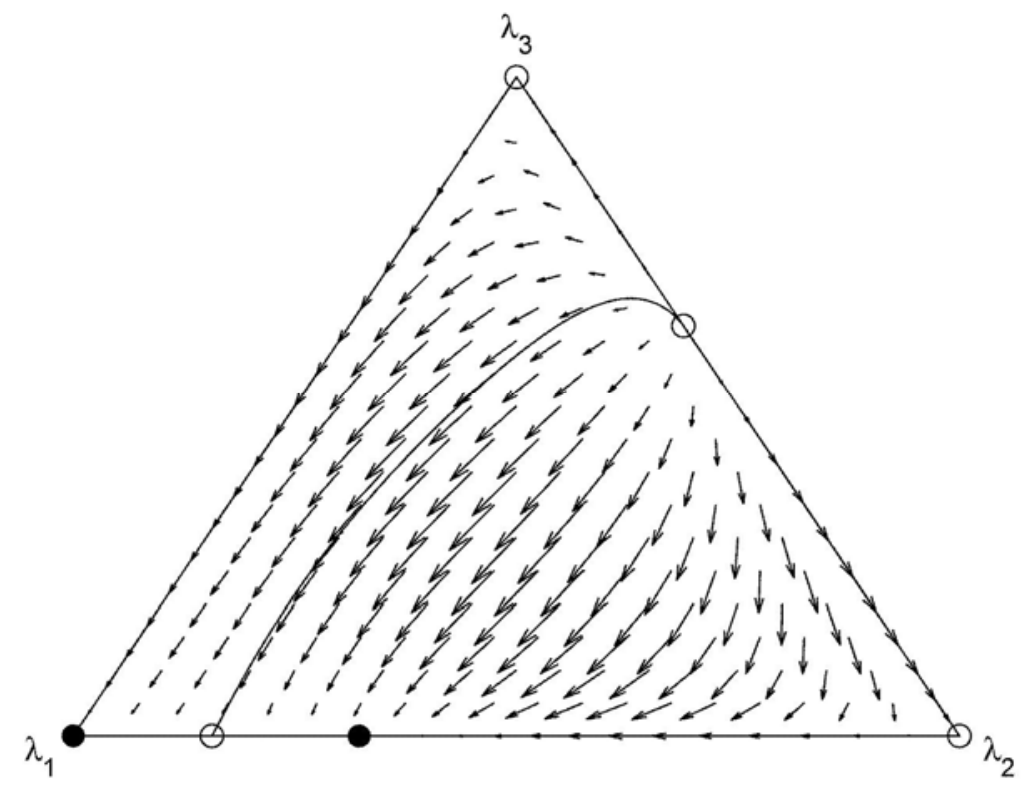

Figure 2. Three-region migration dynamics. In this case lower transport costs lead to multiple long-term equilibria, at different levels of agglomeration $\left(\tau_{12}=2.0, \tau_{13}=2.0, \tau_{23}=1.5\right)$.

The example illustrated in Figure 2 represents a stylised version of actual systems of regions, where a 'region' is defined to be geographical area with around 100,000 to 500,000 inhabitants ${ }^{11}$. The system exhibits clear trends of out-migration from the smallest region and in-migration to the largest region, in line with empirical migration patterns ${ }^{12}$. The initial allocation of manufacturing is important as there are two stable long-term equilibria to which the system may converge, depending on which side of the watershed border the initial distribution lies on.

\footnotetext{
${ }^{11}$ This is intended to correspond to a NUTS level 2 or 3 region in the EU, a smaller entity than most US states or Canadian provinces, and a prefecture or one level smaller in Japan.

${ }^{12}$ In the EU, migration data for the period from 1995 to 2004 for the 27 current members display a positive correlation between net-migration and both population density and GDP per capita (Commission, 2007). Data for the US for 2000 to 2004 indicate a similar trend, with in-migration to prosperous cities, particularly in the South and West, and out-migration from old industrial centres in the Midwest and from poorer rural areas (US Census Bureau, 2006). In Japan, data for the period from 2000 to 2005 at the prefecture level indicates a tendency for migration to occur in the direction of regions with higher population densities and higher GDP per capita (Statistics Bureau, 2009).
} 
Figure 2 represents a type of scenario that does not appear in a symmetric system ${ }^{13}$. Here, depending on the initial allocation, there are two possible levels of agglomeration of manufacturing activity: either complete agglomeration to region 1, or partial agglomeration with manufacturing spread between regions 1 and $2^{14}$. With this level of transport costs, region 3 has too small a fixed population to survive as a manufacturing centre in the long-run, while region 1 always supports some level of manufacturing. Region 2, however, may or may not support manufacturing in the long-run, depending on whether its initial level of manufacturing is above or below the threshold represented by the watershed border.

The case illustrated in Figure 2 yields migration dynamics that broadly correspond to those currently observed in practice for regions on the scale defined above. In Europe, the United States, and Japan, agglomeration is occurring such that the regions with the largest concentrations of population and economic activity tend to be rapidly growing in population while the strongest out-migration tends to be from sparsely-populated, peripheral regions (Commission, 2007; US Census Bureau, 2006; Statistics Bureau, 2009). Similar patterns of migration are repeated throughout both the developed and the developing worlds. Indeed, in the most recent United Nations estimates, the only country predicted to have a smaller proportion of its population living in urban areas in 2050 than in 1950 is Saint Helena, a British territory in the South Atlantic Ocean with around eight thousand inhabitants (United Nations, 2007). In a three-region setting, these dynamics are well represented by the case shown in Figure 2, in which the region that is structurally the largest is gaining in population,

\footnotetext{
${ }^{13}$ In a symmetric system, manufacturing must either agglomerate entirely to a single region, in which case any of the regions would support such an agglomeration, or disperse evenly between the three regions.

14 The long-term distribution of manufacturing in the equilibrium where manufacturing is spread between regions 1 and 2 is $0.6773,0.3227$, and 0.0000 for regions 1,2 , and 3 , respectively. The long-term distribution of manufacturing in the equilibrium where manufacturing is fully agglomerated in region 1 is simply 1.0000, 0.0000 , and 0.0000 .
} 
the smallest region is losing population, and the intermediately-sized region is experiencing relatively neutral population change ${ }^{15}$.

Furthermore, the parameters chosen for the scenario in Figure 2 are appropriate to the analysis of regional policy as they generate migration it is often at such a scale that regional policies are applied in practice. For instance, the EU currently applies its Structural Funds at NUTS level 2, at which roughly two thirds of regions have between 50,000 and 2,000,000 inhabitants (Commission, 2007). Though there certainly exist real systems of regions with dynamics that would be better approximated by other sets of parameters, the scenario displayed in Figure 2 represents common, realistic dynamics and is used as the base case for the analysis that follows. As the intention here is to point out a potential pitfall in the design of regional policy, rather than to provide a universally applicable analysis of it, the scenario represented by Figure 2 need only be accepted as a possibility.

Extensions to scenarios with higher or lower transport costs, in which manufacturing does not agglomerate at all or agglomerates to a single region, are detailed in Appendix 1. A discussion of further cases that appear for different combinations of numbers of agricultural workers and transport costs, which in general do not add insight into regional subsidies that cannot be gained either from the two-region case or from the three-region examples given above, is presented in Appendix 2.

\section{Effects of regional subsidies}

Regional subsidies normally function as a system of subsidies or transfers to those regions with the least economic activity or the lowest standards of living. In the model presented

\footnotetext{
${ }^{15}$ The parameters are chosen to generate realistic dynamics, rather than by calibrating each individual parameter to a realistic value. As the model is highly stylised, calibrating individual parameters would in any case be a subjective and somewhat arbitrary exercise.
} 
here this corresponds to subsidising region 3 and perhaps also region 2, as these regions are generally poorer due to their smaller structural sizes. In the short-run, a subsidy is unequivocally beneficial to individuals in the recipient region as it artificially reduces the costs of production, leading to a larger variety of locally-produced goods, and represents a transfer of tax revenue from other regions, increasing incomes in the subsidised region relative to elsewhere ${ }^{16}$. The changes in relative welfare levels alter migration patterns, which can lead to less obvious long-term effects on welfare.

In a model with only two regions, subsidising a region that has a lower standard of living promotes equality as it increases welfare in the poorer region in the short-term while also weakly increasing its manufacturing share in the long-term. This result extends to a subset of three-region systems, in particular those that are highly symmetric, or in which either agglomeration or dispersion forces generally predominate ${ }^{17}$. The case illustrated in Figure 2, which exhibits migration dynamics more representative of a real system of regions on the scale defined above, presents another possible scenario. To understand this scenario, consider the hypothetical initial distribution of manufacturing of $\lambda=(0.50,0.17,0.33)$, represented by the triangle in Figure $3^{18}$. The convergence of manufacturing activity to its stable long-term equilibrium is represented by the arrowed line in Figure 3.

\footnotetext{
${ }^{16}$ A proof of this relationship is given in Appendix 3.

${ }^{17}$ The extension to some cases with a larger number of regions is straightforward. In short, if the dynamics are such that the only long-term equilibria involve full dispersion or full agglomeration, then the effects of subsidies are the same as those that arise in two-region versions of the model. Such cases are discussed in Appendix 1.

${ }^{18}$ With this hypothetical distribution there is actually more manufacturing in region 3 than in region 2 , though region 3 is the 'smaller' region. This distribution is chosen as it allows the main result to be observed more clearly from the diagrams that follow. The main result also applies to initial distributions with less manufacturing in region 3 than in region 2.
} 


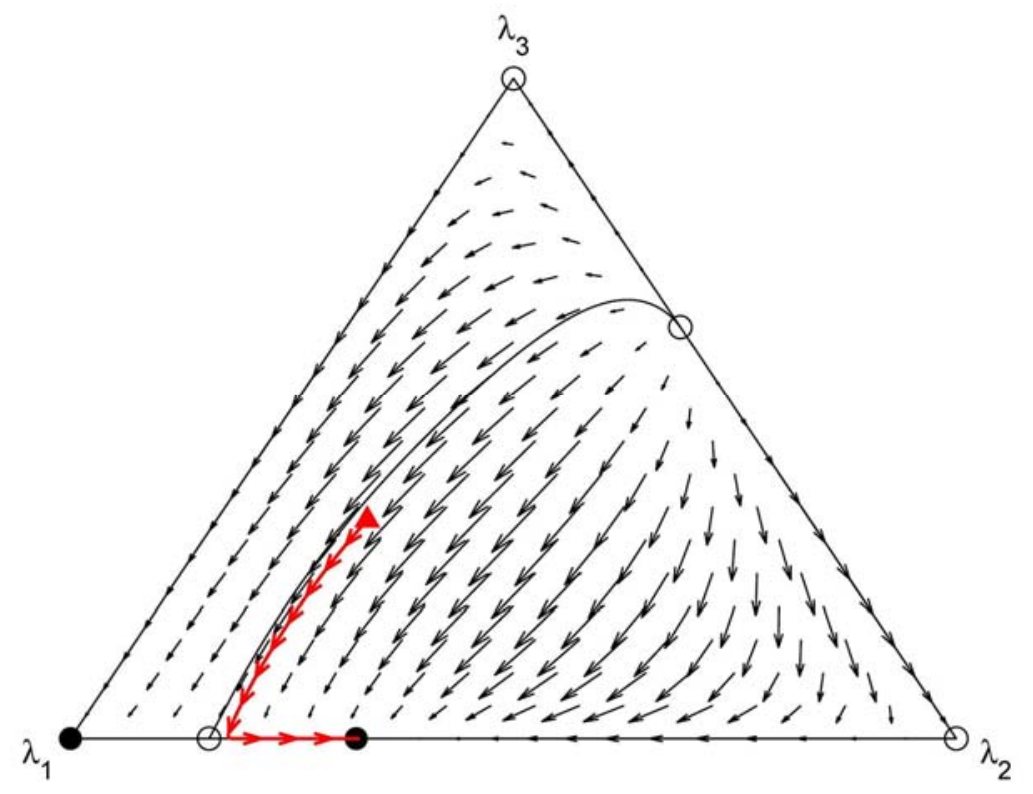

Figure 3. Migration path of manufacturing workers from a hypothetical initial allocation of $\lambda=(0.50,0.17,0.33)$.

In the hypothetical example illustrated in Figure 3, in the beginning manufacturing workers are predominantly migrating away from region 3 and towards region 1 , with relatively little change in the population of region 2. When region 3 has lost all of its manufacturers, region 2 is above the threshold to support manufacturing and it gains manufacturers from region 1 until the stable long-term equilibrium is obtained. Consider now the effect of a subsidy applied to region 3, which is illustrated in Figure 4. 


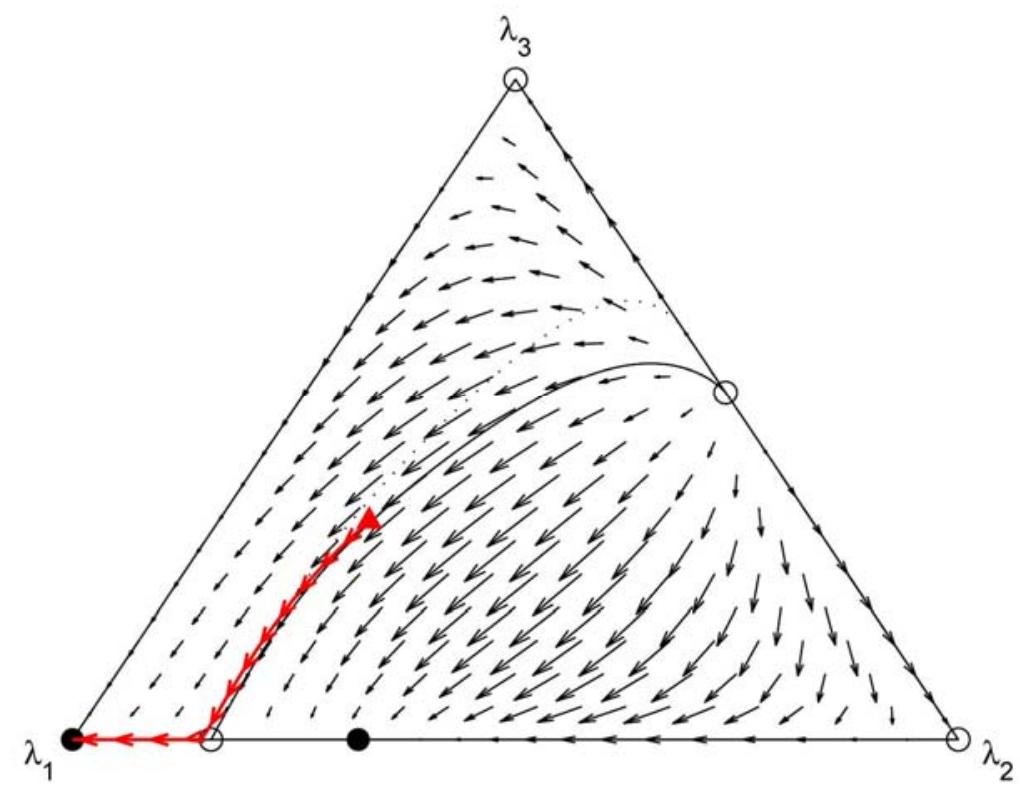

Figure 4. Subsidy applied to region $3\left(s_{3}=0.1\right)$ and resulting migration path of manufacturing from an initial allocation of $\lambda=(0.50,0.17,0.33)$.

The dotted line in Figure 4 represents the watershed border from the case where no subsidy was applied, whereas the solid line represents the watershed border under the subsidy scheme. As we can see from Figure 4, the subsidy shifts the watershed border down and to the right, increasing the range of initial distributions of manufacturing for which there is long-run convergence to the equilibrium in which all manufacturing occurs in region 1 . For the hypothetical initial distribution of manufacturing chosen above, for example, the subsidy causes the system to converge to the fully agglomerated equilibrium. Manufacturing levels in the two stable equilibria are unchanged by the subsidy, as neither involves manufacturing in the subsidised region. Indeed if the allocation of manufacturing were to begin in steady state, then the subsidy illustrated in Figure 4 would not shift the system to a different equilibrium. Rather, there are more initial distributions for which the system converges to the less equitable outcome.

The subsidy makes region 3 a more attractive location for manufacturing in the short-term, slowing out-migration to the two larger regions and even inducing some firms to migrate 
from region 2. Both of these changes worsen conditions for the survival of the cluster in region 2, raising the threshold level of manufacturing in region 2 that is essentially represented by the watershed line. As the shift causes the hypothetical initial allocation from Figure 3 to lie to the left of the threshold line, in this case the cluster in region 2 is broken by the subsidy. Comparing steady state outcomes, the equilibrium in which all manufacturing is agglomerated in region 1 is the worst possible outcome for the welfare of the immobile residents throughout the periphery made up of regions 2 and 3, as all manufactured goods must be transported to these regions from the most distant possible location ${ }^{19}$.

Therefore, in a system in which a general process of agglomeration is occurring and in which some regions are near the threshold for long-term survival, subsidising the smallest, highest out-migration regions can cause somewhat stronger regions nearby to lose their manufacturing bases, resulting in lower welfare for both of these types of peripheral regions and higher welfare in the larger regions that manufacturers migrate to, implying larger interregional inequalities. If future welfare is valued sufficiently, then long-term welfare in the periphery can be reduced and long-term inter-regional welfare inequalities increased.

To understand the shift in the watershed border, first consider that the long-term equilibria with no manufacturing in region 3 are unaltered, as no manufacturing in region 3 implies that no tax or subsidy is being applied, while the subsidy is not large enough to compromise the stability of the stable equilibria. Then, consider that in the short-term the subsidy increases the welfare of manufacturing workers in the subsidised region, in this case region 3 , relative

\footnotetext{
${ }^{19}$ Real agricultural wages in the equilibrium where manufacturing is spread between regions 1 and 2 are 0.4774 , 0.4330 , and 0.3874 for regions 1,2 , and 3 , respectively. In this equilibrium the proportions of manufacturing in the three regions are $0.6773,0.3227$, and 0.0000 for regions 1,2 , and 3 , respectively. In the equilibrium with all manufacturing in region 1 , these wages are $0.4890,0.3706$, and 0.3706 .
} 
to each of the other regions ${ }^{20}$. According to the migration rule (7), this increases the tendency for workers to migrate to the subsidised region from either of the other regions. In the type of case illustrated in Figure 4, in which migration is generally occurring away from region 3 and towards region 1, this results in the overall direction of migration shifting towards region 3, which is reflected in the redirection of the migration arrows clockwise and towards the vertex representing region 3. As a result the watershed border, which by definition follows the direction of migration and terminates at the unstable equilibrium with manufacturing dispersed between regions 1 and 2, shifts down and to the right, expanding the set of cases in which all manufacturing agglomerates to region 1. As the change in shortterm welfare for the manufacturing workers is monotonic and continuous in the level of the subsidy, the magnitude of the shift in the watershed border is also monotonic and continuous, at least up until the threshold level of subsidy at which one of the stable long-term equilibria disappears and therefore so does the watershed border. Indeed, though the numerical examples given in this paper are based on the model outlined in section 2, the result obtains in any other model that exhibits the same agglomeration and dispersion forces, is parameterised to generate the qualitative migration patterns exhibited in Figure 2, and in which the subsidy has the same basic effects on migration dynamics as those explained above.

In Figure 4, the level of subsidy to the firms in region 3 is $10 \%$ of the fixed cost of operation. A different level of subsidy merely results in the same effect to a different degree, as the shift in the watershed border is monotonic and continuous in the size of the subsidy. Therefore, a larger subsidy would alter the long-run equilibrium for a larger range of initial distributions and vice versa. However, with a large enough subsidy to region 3, a two-region equilibrium

\footnotetext{
${ }^{20}$ See Appendix 3 for a proof of this relationship.
} 
would emerge with manufacturing spread between regions 1 and 3. This would be a more equitable outcome than the fully-agglomerated alternative but in such a scenario the equilibrium would be subsidy-dependent: upon removal of the subsidy, the system simply converges to the equilibrium with complete agglomeration to region 1.

Consider now the case illustrated in Figure 2, but with the hypothetical initial distribution of manufacturing of $\lambda=(0.55,0.12,0.33)$, represented by the triangle in Figure 5 . The pattern of migration in manufacturing is again represented by the arrowed line.

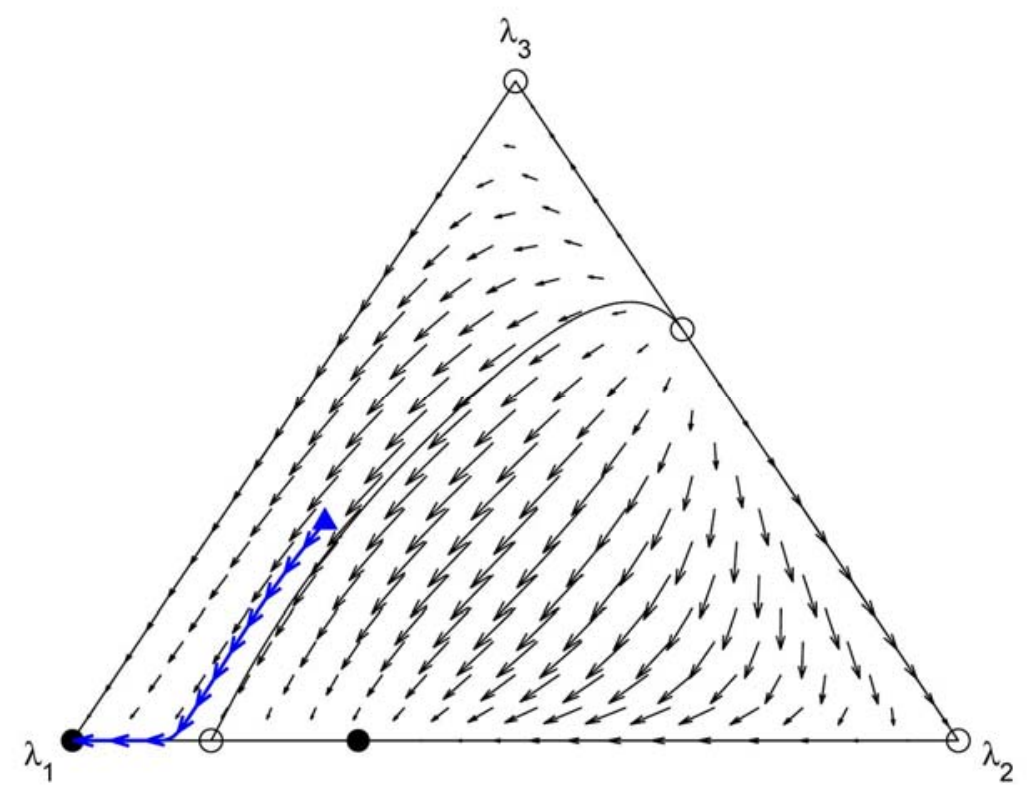

Figure 5. Migration path of manufacturing workers from a hypothetical initial allocation of $\lambda=(0.55,0.12,0.33)$.

Now consider the case of a subsidy being applied to region 2, which is illustrated in Figure 6. The level of the subsidy is $5 \%$ of firms' fixed costs, which represents roughly the same aggregate amount of government expenditure as the $10 \%$ subsidy to the smaller region in Figure 4 for allocations in which the distribution of manufacturing resembles that of agriculture. 


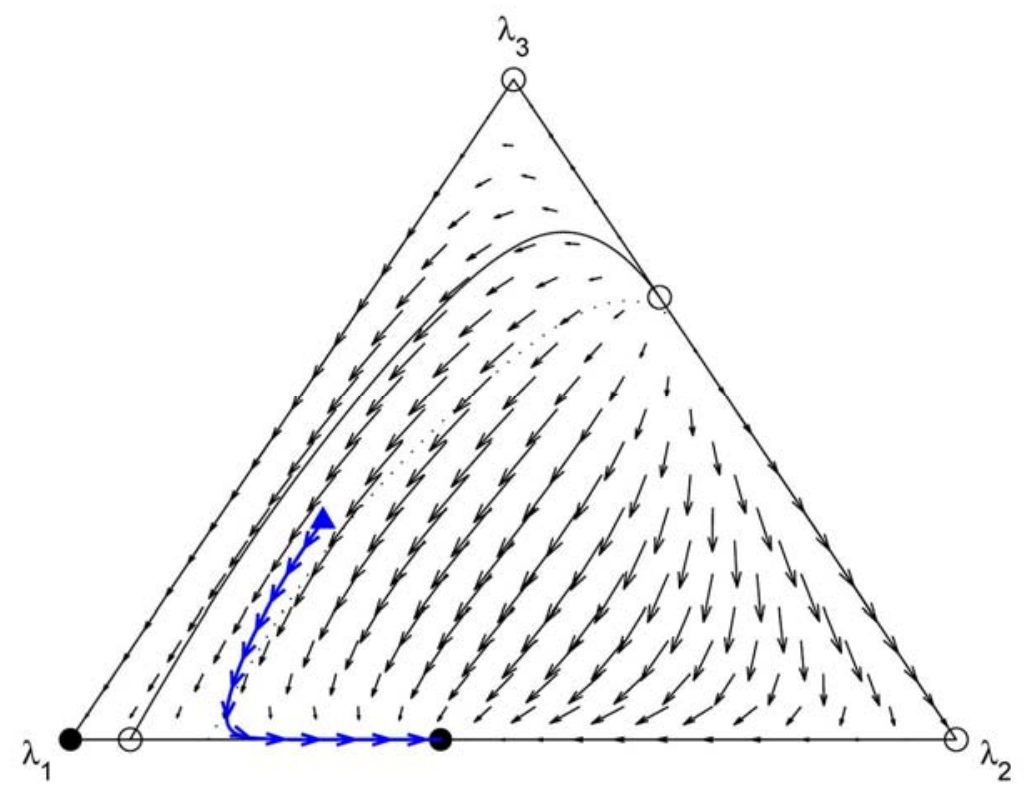

Figure 6. Subsidy applied to region $2\left(s_{2}=0.05\right)$ and resulting migration path of manufacturing from an initial allocation of $\lambda=(0.55,0.12,0.33)$.

We observe from Figure 6 that applying the subsidy to the intermediately-sized region has the opposite effect from applying the subsidy to the smallest region. Here the range of initial distributions for which there is complete agglomeration to region 1 in the long-run contracts, so that in a larger range of cases manufacturing ends up being spread between regions 1 and 2. For the hypothetical initial distribution of manufacturing chosen here, for example, some manufacturing occurs in region 2 in the long-run when the subsidy is applied. In the context of a country with many regions that is experiencing internal migration, this result corresponds to a larger number of intermediately-sized regions supporting manufacturing in the long-term. Furthermore, the subsidy increases the amount of manufacturing in region 2 in the dispersed equilibrium. Both of these factors lead to higher standards of living for the immobile workers in regions 2 and $3^{21}$.

\footnotetext{
${ }^{21}$ Real agricultural wages when manufacturing is spread between regions 1 and 2 are 0.4665, 0.4484, and 0.3933 for regions 1, 2, and 3, respectively; somewhat lower for region 1 but higher for regions 2 and 3 than in the base case due to the higher level of manufacturing in region 2. In this equilibrium the proportions of manufacturing in the three regions are $0.5822,0.4178$, and 0.0000 for regions 1,2 , and 3 , respectively, whereas
} 
Therefore, subsidising regions within the periphery that are potentially sustainable centres of economic activity in the long-run may lead to a reduction in the overall acuteness of agglomeration and less inter-regional inequality. This result favours the promotion of 'regional centres' within the periphery that can provide reasonably local production and employment. Again, the shift in the watershed border is larger the higher is the level of the subsidy, while in this case the level of manufacturing in region 2 in the dispersed stable longterm equilibrium is also increasing in the level of the subsidy. Furthermore, the unstable long-term equilibrium with manufacturing spread between regions 1 and 2 shifts in the direction of region 1 as the level of the subsidy increases, which contributes to the shift to the left in the watershed border.

Applying regional subsidies to both region 2 and region 3 is simply an extension of the two examples shown above, with the effects of the two subsidies working in opposite directions. Therefore, not only is a subsidy to the intermediate region potentially beneficial for the two smallest regions, but the benefit would be greatest if no concurrent subsidy were applied to the smallest region.

The emergence of the above phenomena is of course dependent on the selection of structural parameters that generate the dynamics displayed in Figure 2, so it natural to question how important the parameter choices are to producing these phenomena. This is difficult to address comprehensively as allowing all of the structural parameters to vary effectively implies a five-dimensional parameter space. Nevertheless, it is possible to observe the parameter spaces for structural sizes and transport costs separately, taking slices of the overall parameter space, which is sufficient to demonstrate that the main result obtains for a sizeable 
range of parameter values; this exercise is carried out in Appendix 2. The parameters chosen above are further endorsed by their generation of realistic stylised dynamics, which lead intuitively to the result that subsidies enhance overall agglomeration in the system.

In addition, though the result is dependent on the selection of parameter values within a certain range, the range for which the negative effect presented above arises is larger the more regions are included in the model. As discussed above, three regions is the minimum number for this effect to arise. With an increase in the number of heterogeneous regions in a system, the likelihood of the subsidy reducing long-term welfare in at least one recipient region by breaking a nearby manufacturing cluster only increases. So the larger the system, the broader the range of parameter values for which the result applies to at least one region.

\section{Conclusion}

This paper demonstrates a potential pitfall in the design of regional policy that results from patterns of migration. As noted by Lindbeck (1964), externalities in production can imply that a subsidy to region can have the effect of damaging the integrity of a nearby cluster, which may be to the detriment of residents of both of these regions. This idea is formalised here in an extension of the Krugman (1991) core-periphery model, an intuitive general equilibrium framework that includes externalities in production and the possibility of migration for both firms and individuals. By extending the model to include a government able to allocate subsidies that it funds through taxation, it is possible to evaluate the effects of regional subsidies. The model demonstrates that a subsidy to a poor region may cause a disproportionately large out-migration from a larger, nearby region, which makes residents of both regions worse off in the long-run.

This result should be of concern to the designers of regional policy, as it raises the possibility of the effects of a subsidy being, in some cases, the opposite of what is intended. The result 
also signals the importance of migration to the effects of regional policy. Rather than allocating subsidies solely on the basis of the relative production and income levels of different regions, the most effective policy may involve strengthening relatively remote regions that have characteristics that would enable them to survive as clusters. In other words, the optimal design of regional policy may involve the focusing of funds on certain regions, in order to establish healthy regional centres throughout the economy. In this way, market access for all regions could be promoted at attainable and relatively equitable levels.

Further research is required to identify the conditions under which poor-region subsidies would have the type of negative long-term effect on the welfare of the recipient region's residents that is presented in this paper. However, the results favour subsidising poorer regions that have a greater possibility of sustaining production, so it is possible that the relevant factors could include a region's physical geography, natural resources, location at a natural transport node such as a harbour, portage, or fork in a valley, or manmade factors such as transport infrastructure or the presence of substantial populations of workers or firms. The investigation of how the effect of poor-region subsidies on migration patterns and thereby on welfare levels depends on these and other potential factors lies beyond the scope of this paper, but presents interesting topics for future research.

\section{References}

Baldwin, R. E. 1999. The core-periphery model with forward-looking expectations. NBER Working Paper No. W6921.

Baldwin, R. E., and Okubo, T. (2006) Heterogeneous firms, agglomeration and economic geography: spatial selection and sorting. Journal of Economic Geography, 6(3): 323346.

Commission. 2006. Verification of additionality in the objective 1 regions for 2000-2006. Brussels: Directorate-General Regional Policy, European Commission.

—. 2007. Growing regions, growing Europe: fourth report on economic and social cohesion. Luxembourg: Office for Official Publications of the European Communities. 
—. 2008. EU Cohesion Policy 1988-2008: Investing in Europe's future. Luxembourg: Office for Official Publications of the European Communities.

Dupont, V., and Martin, P. 2006. "Subsidies to poor regions and inequalities: some unpleasant arithmetic,” Journal of Economic Geography, 6, 223-240.

Faini, R. 1983. "Cumulative process of deindustrialisation in an open region: the case of southern Italy 1951-1973,” Journal of Development Economics, 12, 277-301.

Fujita, M., Krugman, P.R., and Venables, A.J. 1999. The Spatial Economy: Cities, Regions, and International Trade. Cambridge, MA: MIT Press.

Holl, A. 2004. "Manufacturing location and impacts of road transport infrastructure: empirical evidence from Spain,” Regional Science and Urban Economics, 34, 341363.

Krugman, P.R. 1991. “Increasing returns and economic geography,” Journal of Political Economy, 99, 483-499.

Lindbeck, A. 1964. “Location policy,” Skandinaviska Banken Quarterly Review, 4, 41-51.

Martin, P. 1999a. "Public policies, regional inequalities and growth,” Journal of Public Economics, 73, 85-105.

—. 1999b. “Are European regional policies delivering?” EIB Papers, 4, 10-23.

Martin, P., and Rogers, C.A. 1995. "Industrial location and public infrastructure,” Journal of International Economics, 39, 335-351.

Matsuyama, K., and Takahashi, T. 1998. "Self-defeating regional concentration,” Review of Economic Studies, 65, 211-234.

Statistics Bureau. 2009. Japan Statistical Yearbook. Tokyo: Ministry of Internal Affairs and Communications.

Teixeira, A.C. 2006. "Transport policies in light of the new economic geography: the Portuguese experience,” Regional Science and Urban Economics, 36, 450-466.

Ulltveit-Moe, K.H. 2007. "Regional policy design: an analysis of relocation, efficiency and equity,” European Economic Review, 51, 1443-1467.

United Nations. 2007. World Urbanization Prospects: The 2007 Revision Population Database. New York, NY: Population Division of the Department of Economic and Social Affairs of the United Nations Secretariat.

US Census Bureau. 2006. Domestic Net Migration in the United States: 2000 to 2004. Washington, DC: United States Department of Commerce, Economics and Statistics Administration. 


\section{Appendix 1}

Migration dynamics of the qualitative type represented by Figure 2, in which manufacturing activity agglomerates to either the largest region or the two largest regions in the long-term, arise for parameter values that fall within a particular range. In order to understand the model and the parameters that generate such dynamics, it may be helpful to consider the dynamics that arise from other sets of parameter values. In this appendix, the cases that arise for lower and higher transport costs are considered. These cases produce dynamics that differ from Figure 2 in ways that are qualitatively similar to changing the values of other model variables, as the effect of each on migration dynamics is through either a weakening or a strengthening of agglomeration forces. Appendix 2 presents a comprehensive analysis of the parameter spaces for both transport costs and structural sizes.

The type of scenario that arises with high transport costs is illustrated in Figure 7, using the same parameter values as in Figure 2 but with transport cost parameters $\tau_{12}=3.0, \tau_{13}=3.0$, and $\tau_{23}=2.5$.

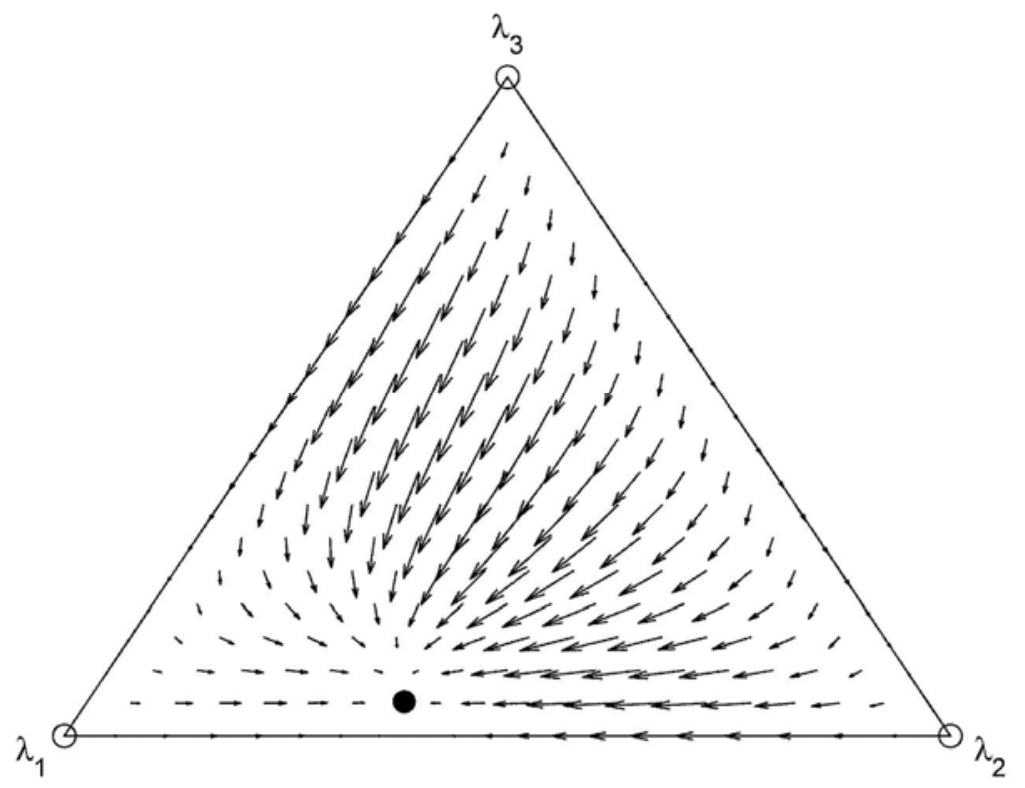

Figure 7. Three-region migration dynamics. In this case transport costs are sufficiently high to create stability in the system $\left(\tau_{12}=3.0, \tau_{13}=3.0, \tau_{23}=2.5\right)$. 
Figure 7 represents an example in which transport costs are sufficiently high that the only stable equilibrium has manufacturing spread between the three regions. The long-term allocation of manufacturing is therefore not dependent on the initial allocation, but is entirely determined by physical geography and other factors captured in the model by the numbers of agricultural workers. This scenario would be appropriate to a system made up of regions that are relatively inaccessible from each other, of regions that each have strong positive characteristics for local demand or production such as a natural port or mineral deposit, or of regions defined to be particularly large in area, for example entire countries. In these cases we would expect each region to support a diverse range of production in the long-term.

In the scenario illustrated in Figure 7, the effects of a subsidy to region 3 on the short- and long-term welfare of agricultural workers in each of the three regions are straightforward. The subsidy to region 3 increases the short-term welfare of agricultural workers in region 3 relative to those elsewhere. Furthermore, the subsidy shifts the long-term equilibrium such that a larger share of manufacturing occurs in region 3 and a smaller share occurs in each of the other two regions, increasing the real wage of agricultural workers in region 3 while decreasing the real wage of agricultural workers elsewhere. Therefore, in the case of a stable system, such as a set of regions on a large scale, in which there is only one possible long-term distribution of manufacturing, subsidising the smallest and poorest region reduces inequality. Appropriate examples could include the Equalization Program in Canada, in which unconditional transfers are made from wealthy to poor provinces.

On the other hand, sufficiently low transport costs will ensure that the only stable equilibria involve agglomeration of all manufacturing activity to a single region. This may involve certain agglomeration to one particular region, agglomeration to one of two regions, or to any of the three. In the first case, there is just one region to which all manufacturing converges 
from any initial distribution. In such a case the subsidy would not change the long-run outcome, unless it is large enough to create a different type of equilibrium; it would simply hasten or slow the process of agglomeration, depending on which region receives it.

In other cases manufacturing could converge to one of two possible regions or to any of the three regions. The case with two possible manufacturing locations does not yield any insight not gained from the cases with one or three potential locations, so we proceed to the case where each region is a potential location for all manufacturing. Such a case is illustrated in Figure 8, using the same parameter values as in Figure 2 but with transport cost parameters $\tau_{12}=1.5, \tau_{13}=1.5$, and $\tau_{23}=1.25$.

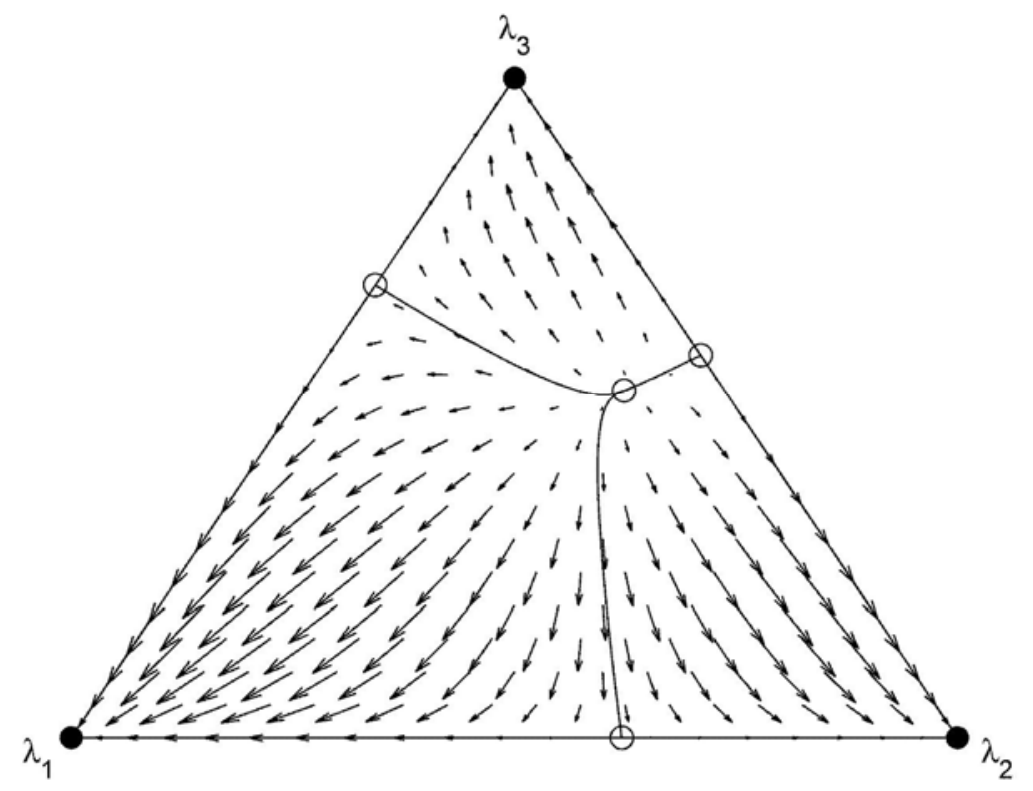

Figure 8. Three-region dynamics with heterogeneous structural sizes and transport costs. In this case transport costs are sufficiently low that the system is unstable $\left(\tau_{12}=1.5, \tau_{13}=1.5, \tau_{23}=1.25\right)$.

In the case illustrated in Figure 8, the effect of a subsidy to any particular region would be to increase the range of initial distributions of manufacturing for which all manufacturing eventually converges to that region. In terms of equality the effects of this are not clear. As agricultural goods are not subject to transport costs, the welfare of workers in the region with all manufacturing does not depend on which region this is. Welfare levels elsewhere depend 
entirely on proximity to the manufacturing centre. The most equitable outcome would therefore be for manufacturing to be located in the location that is most 'central' to the system by some definition, say in terms of shortest maximum distance to any other region or the shortest mean distance to the other regions. In cases with such strong agglomeration, the most effective policy for promoting equality is highly dependent on geography and could involve subsidising regions anywhere along the spectrum of production and income levels.

\section{Appendix 2}

As the analysis in this paper is based on particular cases that emerge in the dynamics of a heterogeneous system of three regions, it is natural to question to what degree the results are dependent on the parameter choices and what other cases could emerge if different parameters were selected. An ideal answer to both of these queries would involve a comprehensive analysis of the parameter space, which is problematic because the model has six structural parameters. Therefore, even if we retain the simplifying assumption that regions 2 and 3 are equidistant from region 1, the parameter space is five-dimensional, which renders it practically impossible to represent in a meaningful way. It is possible, however, to observe the parameter spaces for each of the two types of structural parameters, transport costs and the numbers of agricultural workers, while holding the other fixed.

\section{Transport costs}

A three-region system comprises three pairs of regions, each of which would potentially have a different transport cost parameter, though to simplify things somewhat the convention that $\tau_{12}=\tau_{13}$ is retained. We may therefore illustrate the types of equilibria that emerge across the parameter space for transport costs on a two-dimensional plot. This is done in Figure 9, in which the underlying parameters and the numbers of agricultural workers are kept the same as in the example presented in Figure 2, so that $L_{1}^{A}=3, L_{2}^{A}=2$, and $L_{3}^{A}=1$. 


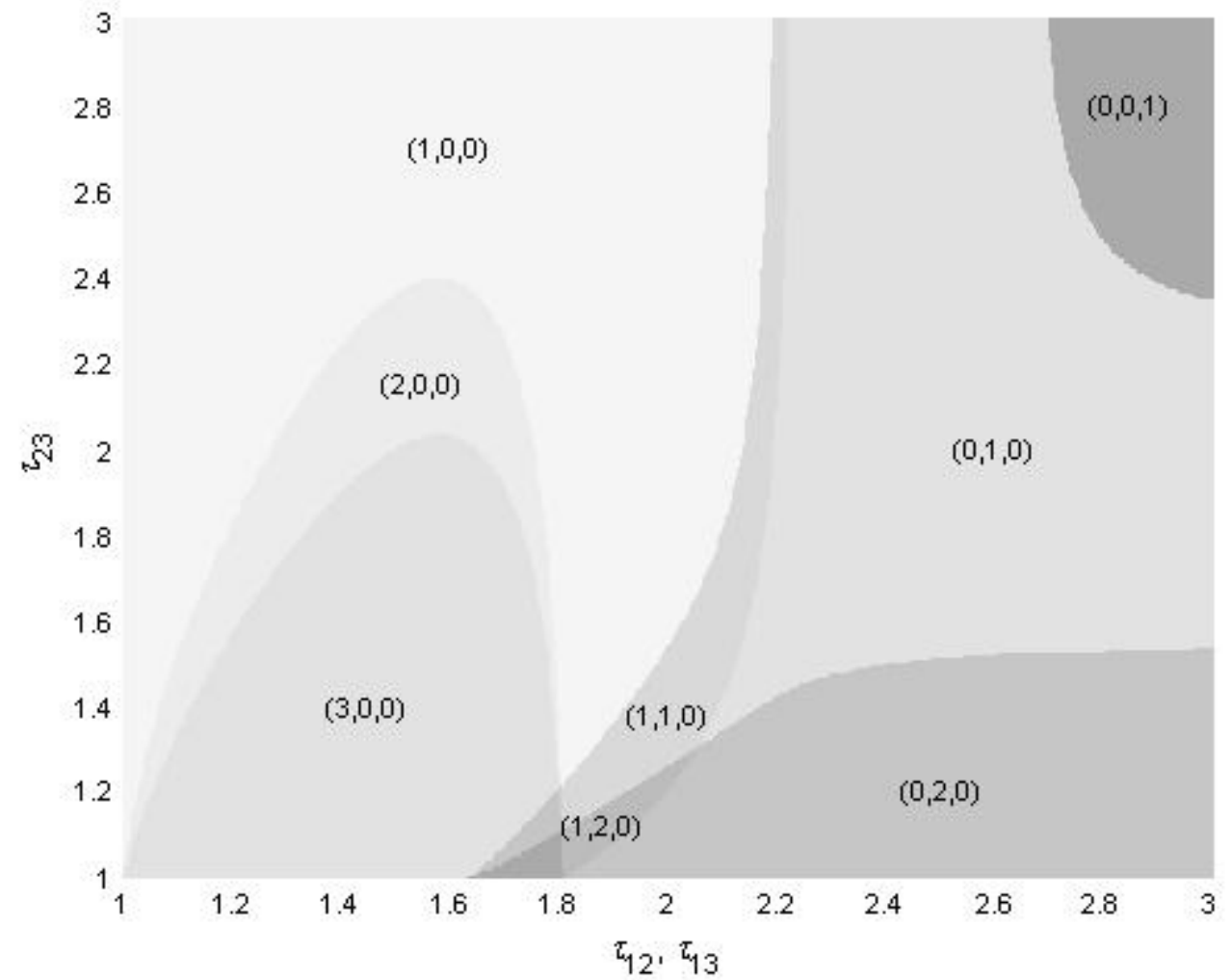

Figure 9. Parameter space for transport costs.

The shading given to each point in Figure 9 represents the types of long-run equilibria that can occur for each combination of parameter values, so that an area with a common shade represents a set of parameter values that generate the same types of stable long-run equilibria. The 'type' of a single equilibrium is defined as the number of regions that support a positive level of manufacturing. The types of equilibria that emerge for given parameter values are summarised as counts of the one-, two-, and three-region equilibria, which are represented by the labels. For example, $(1,0,0)$ represents one completely agglomerated equilibrium, so for any initial distribution it is certain that manufacturing agglomerates to one particular region, whereas $(3,0,0)$ represents a case where manufacturing completely agglomerates but may do so to any of the three regions. Likewise, $(0,2,0)$ represents two possible long-run equilibria, each with manufacturing spread between two regions. 
It is clear from Figure 9 that the equilibria with complete agglomeration to a single region tend to appear when transport costs are low, particularly between region 1 and the other two regions, while complete dispersion in the long-run requires high transport costs between each pair of regions. Two-region equilibria emerge for an intermediate range of transport costs. The cases in which the subsidy to the poorest region leads to complete agglomeration for a larger range of starting values appear in the overlap between parameter values that produce one- and two-region equilibria, largely comprised of the area labelled $(1,1,0)$ that includes the case illustrated above in Figure 2. Just below this is a smaller area labelled $(1,2,0)$, representing parameters for which there is also a long-term equilibrium with manufacturing spread between regions 1 and 3. Each of the scenarios in which both one- and two-region equilibria are possible includes a range of initial allocations for which a subsidy to the intermediate region reduces inequality by shifting the equilibrium towards the periphery.

A number of different cases appear for extremely low values of the transport costs between regions 2 and 3, some of which exhibit the negative effect on equality of the poor-region subsidy, though in the interests of space these are not explored in detail.

\section{Numbers of agricultural workers}

As individuals in the model each spend a fixed proportion of their income on the agricultural good, which is produced under constant returns to scale and sold at a fixed price, a proportional change in the level of agricultural production in all regions simply leads to a change in the prices of all manufactured goods by the same proportion; real manufacturing wages would be scaled up and migration dynamics would not be affected. Therefore, in observing the types of long-run equilibria that emerge, the distribution of agricultural workers across regions may be fully characterised by the proportion in each region, so we may represent all possible combinations of numbers of agricultural workers on a ternary plot. This is done in Figure 10, in which the transport cost parameters are fixed at the same levels 
as in the case presented in Figure 2, with $\tau_{12}=2.0, \tau_{13}=2.0$, and $\tau_{23}=1.5$, while the underlying parameter values are kept the same. The same labelling convention as in Figure 9 is used to identify the types of equilibria.

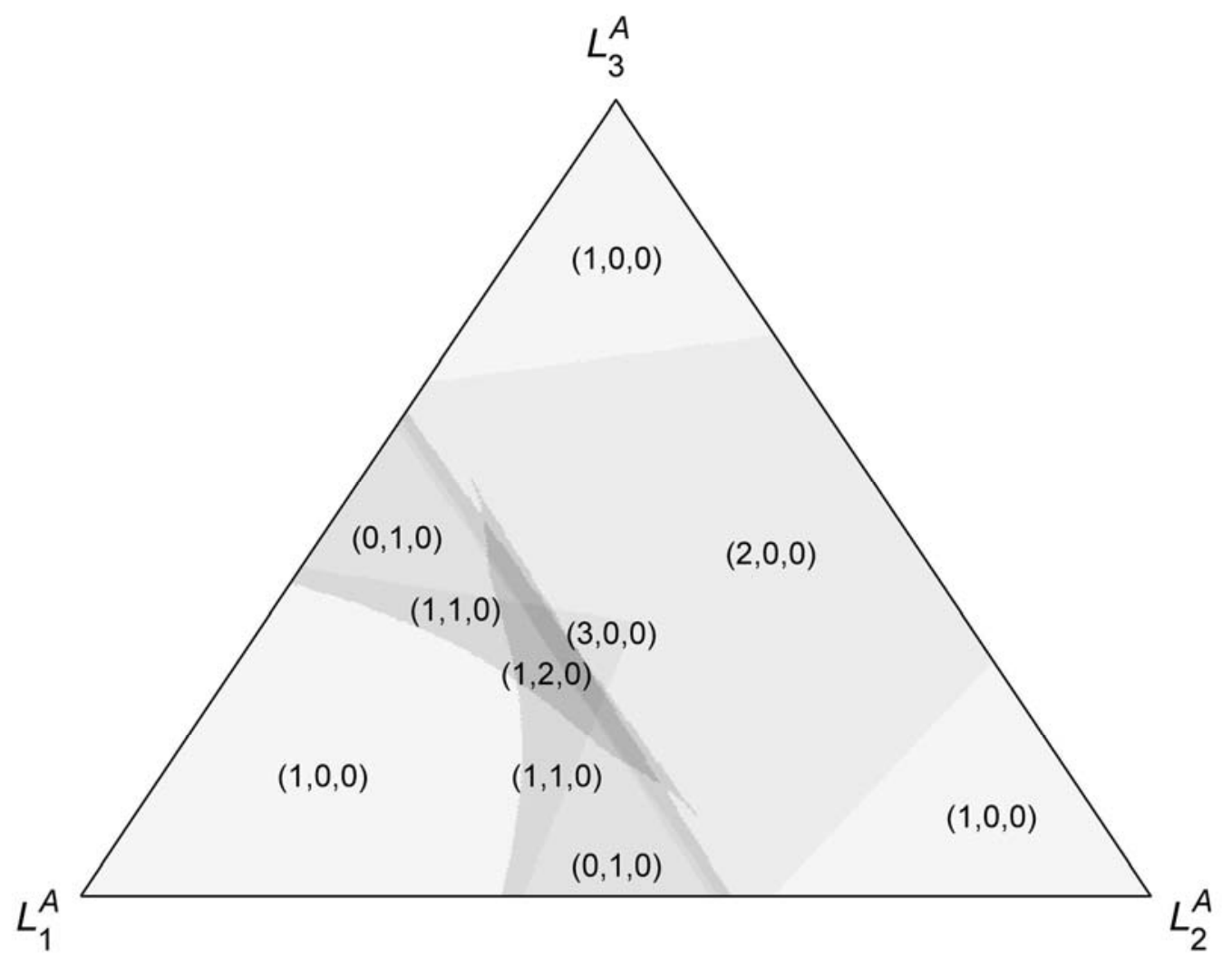

Figure 10. Parameter space for the numbers of agricultural workers.

Figure 10 demonstrates that if the mass of agricultural workers is highly concentrated in any one region, then this region necessarily attracts all manufacturing activity in the long-run. This reflects the tendency for a region with a larger structural size, which implies a larger local market, to attract and support more manufacturing activity. If the agricultural workers are more evenly spread, then more than one region may support manufacturing in the longterm. For cases where agricultural workers are more evenly spread between the regions, in which at least two regions have a large enough structural size to support manufacturing in the long-term, two-region equilibria emerge. For example, with agricultural workers evenly spread between region 1 and either region 2 or region 3, with few agricultural workers in the 
remaining region, a single two-region equilibrium exists, reflected by the label $(0,1,0)$,. This means that the only possible long-term equilibrium has manufacturing spread between the two larger regions.

If one region has a large enough agricultural population to support manufacturing in the longrun, but not so large as to make this occur in every case, a number of interesting cases emerge. In this range, both one- and two-region equilibria exist, and we have a threshold for convergence to the different equilibria that is affected by subsidies in the manner explained in this paper. The example focused on in this paper has a single one-region equilibrium and a single two-region equilibrium, or $(1,1,0)$. If regions 2 and 3 were more even in size, in the space labelled $(1,2,0)$, then either may support manufacturing in the long-term along with region 1 . In both of these type of cases, a subsidy to the poorest region is able to hurt its inhabitants in the long-run by shifting the economy to a more agglomerated equilibrium.

Several different cases appear for small ranges of parameter values. Again, some of these cases exhibit the negative effect of the poor-region subsidy on equality, but in the interests of space are not explored in detail.

\section{Appendix 3}

From (4), the introduction of a subsidy to region $r$ has the following effects on the numbers of varieties of manufactured goods produced in each region:

$$
\frac{d n_{s}}{d s_{r}}=\left\{\begin{array}{cc}
\frac{(\sigma-1) L_{s}^{M}}{\left[\sigma-(\sigma-1) s_{s}\right]^{2} f}>0 & s=r \\
0 & s \neq r
\end{array}\right.
$$

So the range of varieties is expanded in the subsidised region but remains unchanged elsewhere. It can be seen from the price index (2) that, due to transport costs, this has a larger effect on the welfare of individuals in the subsidised region than elsewhere. 
From (3), the introduction of a subsidy to region $r$ has the following effects on production volumes per manufacturing firm in each region:

$$
\frac{d x_{s}}{d s_{r}}=\left\{\begin{array}{cc}
-\sigma f<0 & s=r \\
0 & s \neq r
\end{array}\right.
$$

So per-firm production volumes decline in the subsidised region but are unchanged elsewhere. The demand by individuals in region $s$ for goods produced in region $r$ is:

$$
x_{r \rightarrow s}=\frac{\tau_{r s}^{1-\sigma} p_{r}^{-\sigma}}{P_{s}^{1-\sigma}} \mu Y_{s}
$$

The ratio of demand in region $s$ for goods produced in region $r$ relative to region $q$ is then:

$$
\frac{x_{r \rightarrow s}}{x_{q \rightarrow s}}=\frac{\tau_{r s}^{1-\sigma}}{\tau_{q s}^{1-\sigma}}\left(\frac{p_{r}}{p_{q}}\right)^{-\sigma}
$$

Therefore:

$$
\frac{d\left(x_{r \rightarrow s} / x_{q \rightarrow s}\right)}{d\left(p_{r} / p_{q}\right)}=-\sigma \frac{\tau_{r s}^{1-\sigma}}{\tau_{q s}^{1-\sigma}}\left(\frac{p_{r}}{p_{q}}\right)^{-\sigma-1}<0
$$

So there is an inverse relationship between the prices of manufactures from two regions and the consumption volumes in region $s$ of goods produced in those regions. As this relationship holds for all destinations, there must by extension be an inverse relationship between the ratios of output prices and output levels of firms in any pair of regions.

Therefore, as per-firm output levels decline in the subsidised region but are unchanged elsewhere, producer prices must rise in the subsidised region relative to all other regions. As manufacturing workers in each region receive nominal wages equal to producer prices, this implies a higher wage relative to goods prices in the subsidised region. Recall also that there is a broader variety of locally-produced manufactures available in the subsidised region. 
These two factors both imply an increased real manufacturing wage in the subsidised region relative to the unsubsidised region. 